\title{
Contraction, fragmentation and expansion dynamics determine nutrient availability in a Mediterranean forest stream
}

\author{
D. von Schiller • V. Acuña $\cdot$ D. Graeber $\cdot$ E. Martí • \\ M. Ribot $\cdot$ S. Sabater $\cdot$ X. Timoner $\cdot$ K. Tockner
}

Received: 24 November 2010/ Accepted: 2 March 2011

(C) Springer Basel AG 2011

\begin{abstract}
Temporary streams are a dominant surface water type in the Mediterranean region. As a consequence of their hydrologic regime, these ecosystems contract and fragment as they dry, and expand after rewetting. Global change leads to a rapid increase in the extent of temporary streams, and more and more permanent streams are turning temporary. Consequently, there is an urgent need to better understand the effects of flow intermittency on the biogeochemistry and ecology of stream ecosystems. Our aim was to investigate how stream nutrient availability varied in relation to ecosystem contraction, fragmentation and expansion due to hydrologic drying and rewetting. We quantified the temporal and spatial changes in dissolved nitrogen $(\mathrm{N})$ and phosphorus $(\mathrm{P})$ concentrations along a
\end{abstract}

This article belongs to the Special Issue "Recent Perspectives on Temporary River Ecology".

D. von Schiller $(\bowtie) \cdot K$. Tockner

Leibniz-Institute of Freshwater Ecology and Inland Fisheries,

Müggelseedamm 301, 12587 Berlin, Germany

e-mail: danielvonschiller@igb-berlin.de

V. Acuña $\cdot$ S. Sabater $\cdot$ X. Timoner

Catalan Institute for Water Research,

Emili Grahit 101, 17003 Girona, Spain

D. Graeber

Department of Freshwater Ecology, National Environmental

Research Institute, Vejlsøvej 25, Silkeborg 8600, Denmark

E. Martí · M. Ribot

Biogeodynamics and Biodiversity Group, Centre for Advanced

Studies of Blanes, CSIC, Accés a la Cala St. Francesc 14,

17300 Blanes, Spain

S. Sabater $\cdot$ X. Timoner

Institute of Aquatic Ecology, University of Girona,

17071 Girona, Spain reach of a temporary Mediterranean forest stream during an entire contraction-fragmentation-expansion hydrologic cycle. We observed marked temporal changes in $\mathrm{N}$ and $\mathrm{P}$ concentrations, in the proportion of organic and inorganic forms as well as in stoichiometric ratios, reflecting shifts in the relative importance of in-stream nutrient processing and external nutrient sources. In addition, the spatial heterogeneity of $\mathrm{N}$ and $\mathrm{P}$ concentrations and their ratios increased substantially with ecosystem fragmentation, reflecting the high relevance of in-stream processes when advective transport was lost. Overall, changes were more pronounced for $\mathrm{N}$ than for $\mathrm{P}$. This study emphasizes the significance of flow intermittency in regulating stream nutrient availability and its implications for temporary stream management. Moreover, our results point to potential biogeochemical responses of these ecosystems in more temperate regions under future water scarcity scenarios.

Keywords Temporary streams - Flow intermittency · Drought $\cdot$ Nitrogen $\cdot$ Phosphorus $\cdot$ Spatial heterogeneity

\section{Introduction}

Temporary streams are running waters that experience a recurrent dry phase (i.e. no surface water or flow intermittency) of varying duration and spatial extent (Williams 2006). Worldwide, these ecosystems comprise a substantial proportion of the total number, length, and discharge of fluvial networks (Larned et al. 2010). For instance, more than half of the total river length in South Africa (Uys and O'Keefe 1997), USA (Nadeau and Rains 2007), and Greece (Tzoraki et al. 2007) is subject to flow intermittency, and in the Arctic and Antarctic regions virtually all 
running waters are temporary (Howard-Williams et al. 1986). In the Mediterranean basin, temporary streams are the dominant surface water type (Gasith and Resh 1999). Furthermore, the duration and extent of flow intermittency is expected to increase globally as a consequence of climate and land use change (Arnell 1999; Huntington 2006; IPCC 2007). In fact, a rapid decline in flow has been already observed along many rivers (Yang et al. 2002; Pasquini and Depetris 2007; Milliman et al. 2008; Stahl et al. 2010).

Nevertheless, temporary streams are mostly neglected in water legislation currently in force. For instance, terms like temporary, intermittent or water scarcity are not even mentioned in the EU Water Framework Directive (WFD 2000). This lack of consideration is probably due to a misleading perception of the representativeness of these ecosystems as well as a lack of scientific knowledge about their fundamental functioning (Larned et al. 2010). Therefore, there is an urgent need to better understand the biogeochemical and ecological implications of flow intermittency as a basis for their sustainable management. Because more and more permanent streams in the temperate zone are becoming temporary, Mediterranean systems may serve as a template for understanding the potential biogeochemical and ecological consequences of stream drying in the temperate zone.

Most Mediterranean temporary streams exhibit a highly dynamic hydrologic regime, characterized by a drying and a rewetting period. In general, stream flow gradually decreases in late spring to early summer (contraction phase), followed by flow cessation and the formation of isolated pools (fragmentation phase), before the surface stream completely dries up (dry phase). At the end of summer, stream flow is re-established either gradually by a decrease in evapotranspiration or abruptly due to heavy rainfall events (expansion phase). This contraction-fragmentation-expansion cycle controls the longitudinal, lateral and vertical hydrologic connectivity along the stream channel network, which has important implications for nutrient availability (Stanley et al. 1997; Dent and Grimm 1999).

During contraction and fragmentation, the concentrations of reduced inorganic forms of nutrients, especially ammonium, tend to increase likely due to the effects of the hypoxic environment (Boulton and Lake 1990; VidalAbarca et al. 2000; Acuña et al. 2005; Lillebo et al. 2007). During stream expansion after rewetting, high concentrations of nitrogen $(\mathrm{N})$ and phosphorus $(\mathrm{P})$ originate from groundwater inputs and from leaching of accumulated organic material (Tzoraki et al. 2007; Obermann et al. 2009; Skoulikidis and Amaxidis 2009). The effect of flow intermittency on the fate of organic $\mathrm{N}$ and $\mathrm{P}$ is less well understood, although an increase in the concentration of dissolved organic N (DON) during stream fragmentation and expansion has been attributed to high microbial production and leaching, respectively (Vazquez et al. 2007; Skoulikidis and Amaxidis 2009; Ylla et al. 2010; Vazquez et al. 2011). Knowledge on the dynamics of organic $P$ is virtually restricted to rewetting periods when the concentration of dissolved organic P (DOP) tends to increase (Tzoraki et al. 2007; Skoulikidis and Amaxidis 2009).

Despite the importance of nutrient limitation to stream communities (Sterner and Elser 2002), the influence of flow intermittency on the relative proportion of $\mathrm{N}$ and $\mathrm{P}$ (i.e. stoichiometric ratios) has rarely been addressed (but see Skoulikidis and Amaxidis 2009). In addition, previous studies assessing temporal changes in nutrient availability during these periods were based on measurements at a single station or done at a weekly or monthly frequency, although changes may occur at smaller time scales and can be highly heterogeneous in space. In this respect, the influence of flow intermittency on the spatial heterogeneity of nutrients has not received much attention despite its importance for a better understanding of controls on community, ecosystem, and landscape-level processes (Pringle 1990; Dent and Grimm 1999; Fisher et al. 2004). Moreover, results from existing studies on this subject are controversial. Some studies uncovered marked increases in the spatial heterogeneity of nutrient concentrations during stream fragmentation (Dent and Grimm 1999; Gómez et al. 2009), whereas others have found no significant effects (Baldwin et al. 2005).

The aim of this study was to investigate how stream nutrient availability varied in relation to ecosystem contraction, fragmentation and expansion due to hydrologic drying and rewetting. To approach this objective, we quantified the spatial and temporal changes of dissolved organic and inorganic forms of $\mathrm{N}$ and $\mathrm{P}$ as well as their stoichiometric ratios along a reach of a temporary Mediterranean forest stream during an entire contractionfragmentation-expansion hydrologic cycle. We hypothesized that ecosystem contraction and fragmentation would enhance the relative importance of in-stream processing on nutrient concentrations, whereas ecosystem expansion would increase the relative importance of external nutrient sources. Based on this hypothesis, we predicted marked temporal changes in nutrient availability during the contraction-fragmentation-expansion hydrologic cycle. Furthermore, we hypothesized that fragmentation would cause spatial segregation of nutrient transformations due to the loss of advective transport. Based on this hypothesis, we predicted an increase in the spatial heterogeneity of nutrient availability during the fragmentation phase, when local in-stream processes predominate over downstream flux. 


\section{Materials and methods}

\section{Study site}

Fuirosos is a temporary forest stream that drains a 15.2$\mathrm{km}^{2}$ granitic catchment in the Montnegre-Corredor Natural Protected Area (Catalonia, NE Spain). It exhibits a Mediterranean climate, with warm, dry summers and mild, humid winters. Monthly mean air temperature ranges from $5^{\circ} \mathrm{C}$ (January) to $24^{\circ} \mathrm{C}$ (August). Annual precipitation varies greatly among years (annual mean $\sim 750 \mathrm{~mm}$ ). Evergreen oaks (Quercus suber and Quercus ilex) and Aleppo pine (Pinus halepensis) dominate at the lower parts of the catchment, whereas deciduous forests of chestnut (Castanea sativa), hazel (Corylus avellana), and oak (Quercus pubescens) are common at higher elevations. Human land use is restricted to dispersed agricultural fields $(<2 \%$ of the catchment).

Stream flow is intermittent, with a dry phase of variable duration and spatial extent among years (Sabater et al. 2001; Butturini et al. 2003; Acuña et al. 2004). At baseflow conditions, the concentration of nitrate $\left(\mathrm{NO}_{3}\right.$; range $\sim 0.01-2.0 \mathrm{mg} \mathrm{N} \mathrm{L}^{-1}$ ) peaks in winter, whereas the concentrations of ammonium $\left(\mathrm{NH}_{4} ;\right.$ range $\sim 0.005-$ $0.15 \mathrm{mg} \mathrm{N} \mathrm{L}^{-1}$ ) and soluble reactive $\mathrm{P}$ (SRP; range $\sim 0-0.02 \mathrm{mg} \mathrm{P} \mathrm{L}^{-1}$ ) peak in summer (Bernal et al. 2005; von Schiller et al. 2008). The concentration of DON (range $\sim 0.1-1 \mathrm{mg} \mathrm{N} \mathrm{L}^{-1}$ ) shows no clear seasonal pattern (Bernal et al. 2005), whereas seasonal data for the concentration of DOP are not available. The stream is considered potentially P-limited for most of the hydrologic period (Sabater et al. 2005; von Schiller et al. 2008).

We selected a 300-m long reach (slope $=0.063 \mathrm{~m} \mathrm{~m}^{-1}$ ) with repeated pools and riffles. Substrate is composed of sand $(60 \%)$ and boulders (30\%), intermixed with patches of cobbles, pebbles, gravel, and bedrock. The streambed is mostly covered by biofilms, with an algal community dominated by diatoms (Tornés and Sabater 2010). Riparian vegetation is well developed and consists mainly of alder (Alnus glutinosa) and sycamore (Platanus $\times$ hispanica), as well as of a dense herbaceous understory. Riparian leaf input peaks in autumn, although intense summer hydric stress causes additional leaf fall during the dry phase (Acuña et al. 2007).

\section{Field sampling}

Sampling was carried out in 2009. During the contraction phase (8 June-4 July) flow gradually decreased. During the fragmentation phase (5 July-23 July) downstream flow ceased and surface water was constrained to isolated pools. An intense rainfall event took place on 10 July and led to a short-term reconnection of surface flow along the entire study reach. The dry phase lasted from 24 July until 22 October. The expansion phase started on 23 October, when a rainstorm increased stream discharge up to $\sim 14 \mathrm{~L} \mathrm{~s}^{-1}$ and reconnected surface flow along the study reach without causing wash-out of materials accumulated on the streambed. After this event, the decrease in air temperature as well as in evapotranspiration maintained a permanent flow until the end of the study (19 November).

During the contraction and expansion phases, we sampled surface water at 3 to 4 -day intervals (totally 24 dates) at 16 locations (at $20 \mathrm{~m}$ distances) each date along the $300-\mathrm{m}$ reach. During the fragmentation phase (i.e. 7 sampling dates), we sampled at the same sampling locations, if water was available, as well as at all additional isolated pools found (i.e. between 5 and 16 locations on a specific date). Sampling was carried out between 0900 hours and 1200 hours to minimize the influence of diel changes.

Surface water was collected from the mid-channel area using a $100-\mathrm{mL}$ syringe (flushed three times prior to use), filtered in the field through ashed Albet (Barcelona, Spain) GF55 glass fiber filters $(0.7 \mu \mathrm{m}$ pore size $)$ into pre-washed plastic containers (1 sample per location), stored on ice, and transported to the laboratory. The glass fiber filters were chosen because they are inert, allow rapid filtration in the field and can be ashed. Dissolved oxygen (DO) saturation, $\mathrm{pH}$ and water temperature were measured at each sampling location on each date using WTW (Weilheim, Germany) hand-held probes.

On each sampling date, we measured the wetted width at fixed cross-sections located at 5-m distances along the reach. During the fragmentation phase, mean wetted width and length of isolated pools was also measured. Based on this information, total wetted area was calculated for each date. Discharge was estimated from measurements of water column depth at the bottom of the study reach at 10-min intervals using a YSI (Ohio, USA) 600-OMS-V2 multiparameter sonde. An empirical depth-discharge relationship was constructed based on several additions of a conservative tracer during the sampling period.

\section{Laboratory analyses}

Samples were stored frozen until analysis, except for $\mathrm{NH}_{4}$ and SRP concentrations, which were analyzed within $24 \mathrm{~h}$ of collection. The concentration of $\mathrm{NH}_{4}$ was analyzed with the salicylate method (Reardon et al. 1966) and the concentration of SRP with the molybdate method (Murphy and Riley 1962) on a Shimadzu (Kyoto, Japan) UV-1800 spectrophotometer. The concentrations of $\mathrm{NO}_{3}$ and chloride were determined on a Shimadzu (Kyoto, Japan) CDD6A ion chromatograph. The concentration of total dissolved $\mathrm{N}(\mathrm{TDN})$ was measured using the high temperature catalytic oxidation method (Merriam et al. 1996) on an 
Analytik Jena (Jena, Germany) multi N/C 3100 analyzer. The concentration of total dissolved P (TDP) was measured as the concentration of SRP (as above) after combined sulfuric acid and hydrogen peroxide digestion at $150^{\circ} \mathrm{C}$ (Zwirnmann et al. 1999). The concentration of dissolved inorganic nitrogen (DIN) was calculated as the sum of $\mathrm{NH}_{4}$ and $\mathrm{NO}_{3}$ concentrations. The concentration of DON was calculated as the difference between TDN and DIN concentrations. The concentration of DOP was calculated as the difference between TDP and SRP concentrations. To further characterize the relative variation of nutrients throughout the study period, we calculated the proportion of inorganic forms relative to the total dissolved concentration of $\mathrm{N}$ (DIN:TDN, in \%) and P (SRP:TDP, in \%) as well as the $\mathrm{N}: \mathrm{P}$ molar ratios of total dissolved forms (TDN:TDP), dissolved inorganic forms (DIN:SRP) and dissolved organic forms (DON:DOP).

Data analysis

To examine temporal patterns of the measured physical and chemical parameters, we explored the relationship between these parameters and the reach wetted area using nonparametric Spearman-rank correlations. The periods before (i.e. contraction and fragmentation phases; 15 sampling dates) and after (i.e. expansion phase; 9 sampling dates) the dry phase were analyzed separately to compare responses under drying and rewetting conditions. To examine spatial heterogeneity, we determined the coefficient of variation $(\mathrm{CV}$, in \%) for each parameter on each sampling date. The relationship between the degree of flow intermittency and the spatial heterogeneity was explored using non-parametric Spearman-rank correlations between wetted area and the $\mathrm{CV}$ of each parameter for each sampling date. Statistical analyses were done using Statistica 6.0 (Statsoft, Tulsa, OK, USA).

\section{Results}

Physicochemical parameters

Stream hydrology varied following the meteorological conditions over the study period (Fig. 1a, b). Discharge and wetted area were strongly related $\left(r_{\mathrm{s}}=0.94, p<0.001\right.$, $n=24$; Fig. $1 \mathrm{~b}, \mathrm{c})$. The gradual stream contraction and fragmentation was interrupted by a short flow pulse (10 July) that reconnected the isolated pools for 3 days. Surface water was absent from the study reach for 91 days until stream flow reconnection occurred at the beginning of the expansion phase. After that, discharge gradually decreased until the end of the study.
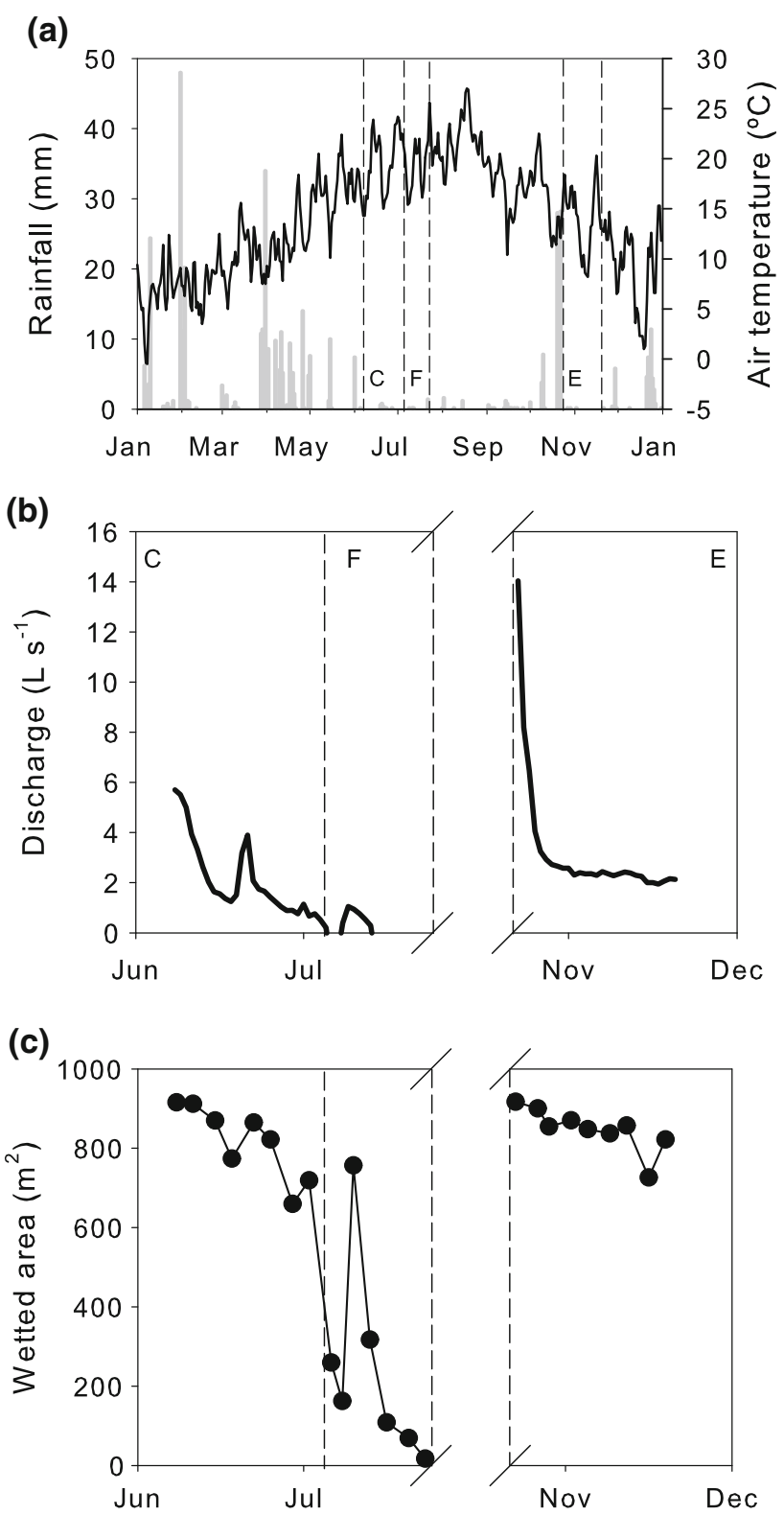

Fig. 1 Temporal variation of: a daily rainfall (grey line) and mean daily temperature (black line) at the study site for the year 2009 as measured at the Collsacreu meteorological station located at the southern limit of the catchment, b daily discharge measured continuously at a permanent station located at the bottom of the study reach, and $\mathbf{c}$ wetted area within the study reach estimated with longitudinal samplings carried out two times per week. Dashed vertical lines separate the hydrologic phases, which are labeled with capital letters ( $\mathrm{C}$ contraction, $\mathrm{F}$ fragmentation, $\mathrm{E}$ expansion). Breaks in the $x$-axis indicate the dry (no surface water) period

During stream contraction and fragmentation, DO saturation $\left(r_{\mathrm{s}}=0.94, p<0.001, n=15\right.$; Fig. $\left.2 \mathrm{a}\right)$ and $\mathrm{pH}$ $\left(r_{\mathrm{s}}=0.79, p<0.001, n=15\right.$; Fig. $\left.2 \mathrm{~b}\right)$ decreased, while the concentration of chloride increased with the reduction of wetted area $\left(r_{\mathrm{s}}=-0.86, p<0.001, n=15\right.$; Fig. 2c). DO saturation and $\mathrm{pH}$ abruptly dropped with stream 

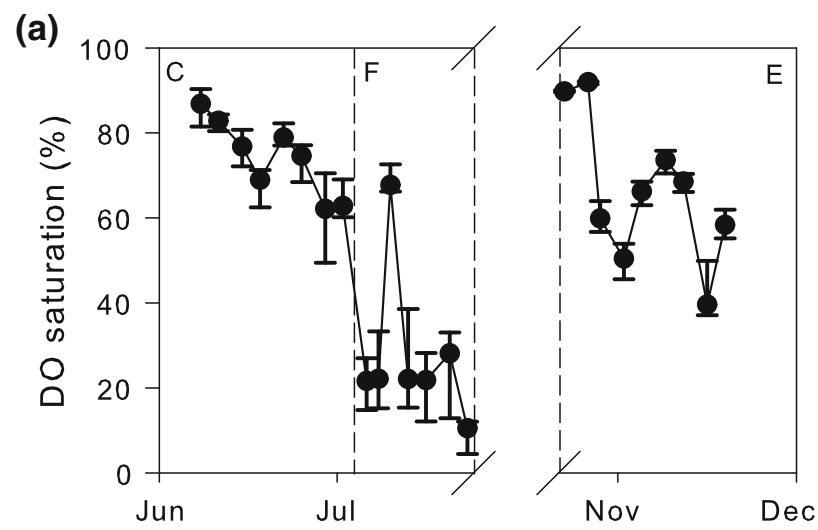

(b)
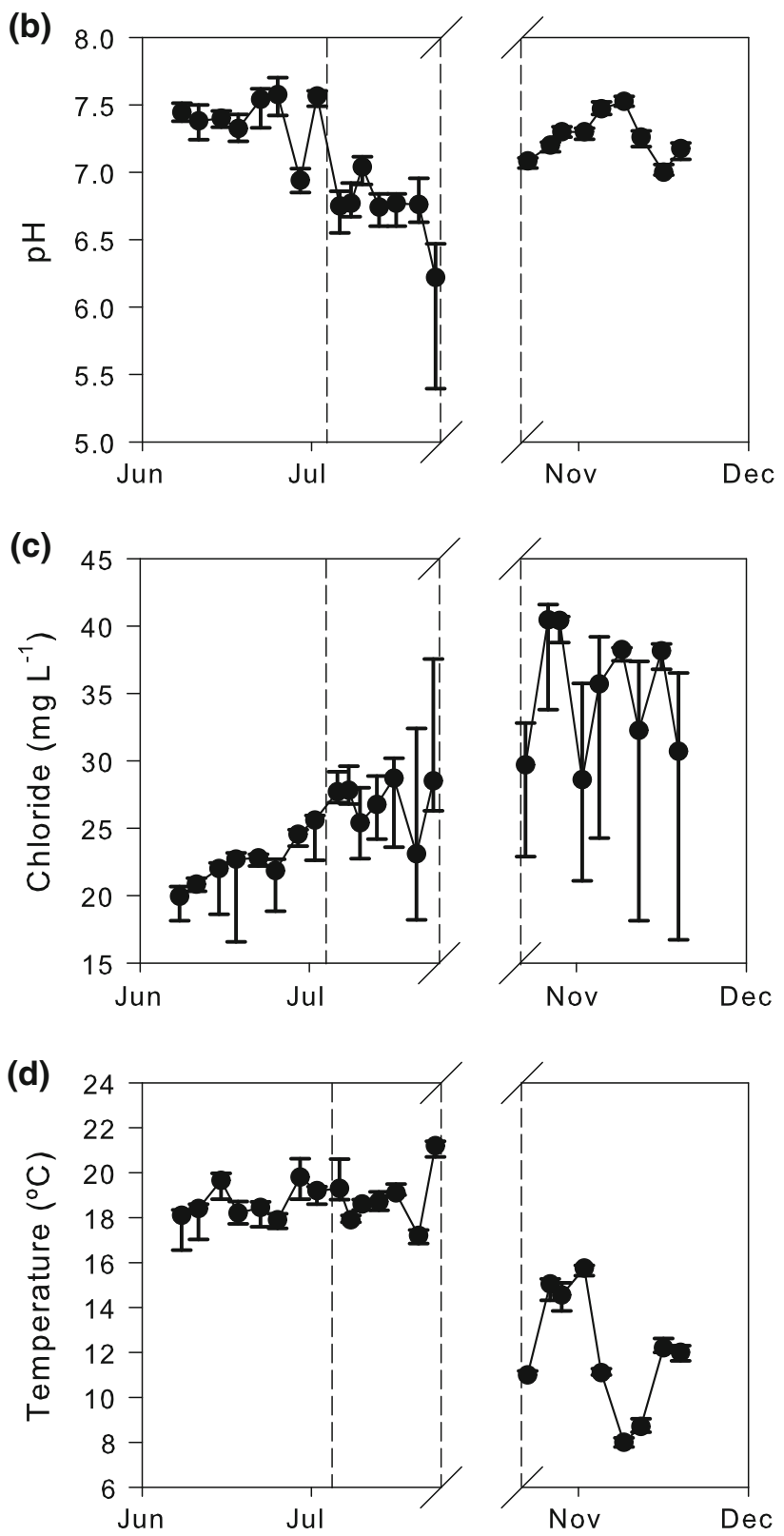

Fig. 2 Temporal variation of: a percent dissolved oxygen saturation, b $\mathrm{pH}$, c chloride concentration, and $\mathbf{d}$ stream water temperature. Dashed vertical lines separate the hydrologic phases, which are labeled with capital letters in the upper panel (C contraction, $\mathrm{F}$ fragmentation, E expansion). Breaks in the $x$-axis indicate the dry (no surface water) period. Data are from samples taken at several locations along the study reach two times per week. Values are the medians \pm quartiles for each sampling date

fragmentation. Conversely, temperature did not show a clear response to stream contraction and fragmentation $\left(r_{\mathrm{s}}=-0.20, p=0.470, n=15\right.$, Fig. $\left.2 \mathrm{~d}\right)$, although the median temperature was $2.7^{\circ} \mathrm{C}$ higher at the end of the fragmentation phase than at the beginning of the sampling period. DO saturation, $\mathrm{pH}$ and chloride quickly responded to the short-term reconnection of the isolated pools. During the expansion phase, only DO saturation responded to the reduction in discharge and wetted area after the initial rewetting $\left(r_{\mathrm{s}}=0.62, p=0.077, n=9\right.$; Fig. $\left.2 \mathrm{a}\right)$, whereas $\mathrm{pH}$, temperature and chloride showed no clear temporal pattern ( $p>0.637, n=9$; Fig. $2 \mathrm{~b}-\mathrm{d})$.

\section{Nutrient concentrations}

Ecosystem contraction, fragmentation and expansion controlled $\mathrm{N}$ and $\mathrm{P}$ dynamics. TDN increased with the reduction of wetted area $\left(r_{\mathrm{s}}=-0.82, p<0.001, n=15\right.$; Fig. 3a), mainly due to an abrupt increase in $\mathrm{NH}_{4}\left(r_{\mathrm{s}}=\right.$ $-0.56, \quad p=0.029, n=15$; Fig. 3b), whereas $\mathrm{NO}_{3}$ $\left(r_{\mathrm{s}}=0.82, \quad p<0.001, \quad n=15 ; \quad\right.$ Fig. $\left.3 \mathrm{~b}\right)$ gradually decreased. DON showed no consistent pattern $\left(r_{\mathrm{s}}=-0.26\right.$, $p=0.302, n=15$; Fig. 3c), except for a sharp increase before drying. The $\mathrm{NO}_{3}: \mathrm{NH}_{4}$ ratio shifted from $>1$ in the contraction phase to $<1$ in the fragmentation phase. Concurrently, TDP increased $\left(r_{\mathrm{s}}=-0.64, p<0.010, n=15\right.$; Fig. 3e) due to increases in both SRP $\left(r_{\mathrm{s}}=-0.50\right.$, $p=0.056, n=15 ;$ Fig. 3f $)$ and DOP $\left(r_{\mathrm{s}}=-0.54\right.$, $p=0.039, n=15$; Fig. 3g). The short-term reconnection of flow briefly reversed trends. The proportion of inorganic to organic $\mathrm{N}$ and $\mathrm{P}$ was relatively stable $(p>0.159$, $n=15$ ). DIN accounted for a median of $18 \%$ of TDN (Fig. 3d) and SRP for $66 \%$ of TDP (Fig. 3h).

At the beginning of the expansion phase, concentrations of most $\mathrm{N}$ and $\mathrm{P}$ forms were high (Fig. 3a-d). However, TDN $\left(r_{\mathrm{s}}=0.70, \quad p=0.036, \quad n=9 ; \quad\right.$ Fig. $\left.3 \mathrm{a}\right), \quad \mathrm{NO}_{3}$ $\left(r_{\mathrm{s}}=0.70, \quad p=0.035, \quad n=9 ; \quad\right.$ Fig. $\left.3 \mathrm{~b}\right) \quad$ and DOP $\left(r_{\mathrm{s}}=0.71, p=0.033, n=9\right.$; Fig. $\left.3 \mathrm{~g}\right)$ decreased consistently with the reduction of wetted area afterwards, while the concentration of $\mathrm{NH}_{4}$, DON, TDP and SRP remained relatively constant ( $p>0.12, n=9$; Fig. 3 ). As a consequence, the proportion of DIN in TDN was as high as $81 \%$ 

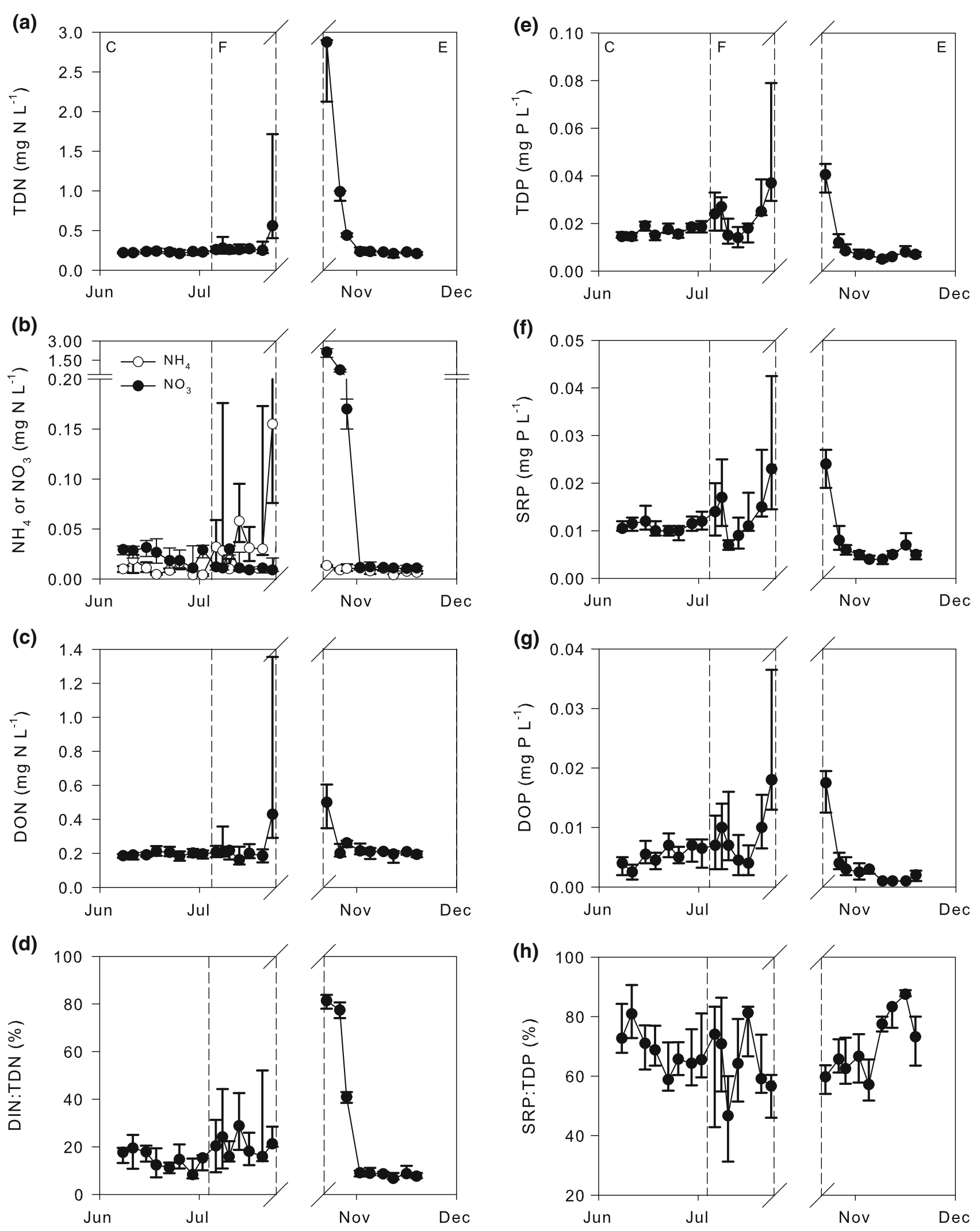

at the beginning of the expansion phase, and then decreased rapidly ( $r_{\mathrm{s}}=0.67, p=0.049, n=9$; Fig. $3 \mathrm{~d}$ ), stabilizing at a median value of $8 \%$ by the end of the study.
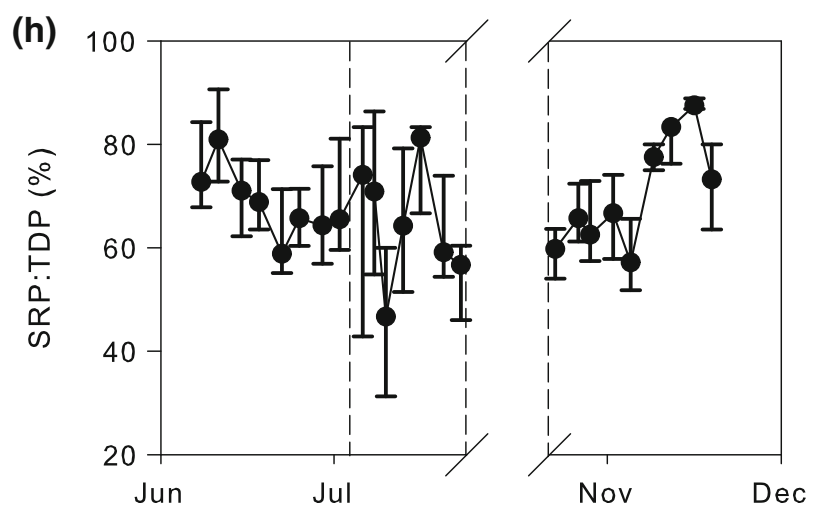

Conversely, the proportion of SRP in TDP remained relatively stable at similar values as in the previous hydrologic phases ( $p=0.150, n=9$; Fig. 3h). 
Fig. 3 Temporal variation of dissolved nitrogen (N) and phosphorus (P) concentrations. Represented are: a total dissolved N (TDN), b ammonium $\left(\mathrm{NH}_{4}\right)$ and nitrate $\left(\mathrm{NO}_{3}\right)$, c dissolved organic $\mathrm{N}(\mathrm{DON})$, d percent dissolved inorganic N in TDN (DIN:TDN), e total dissolved $\mathrm{P}$ (TDP), $\mathbf{f}$ soluble reactive phosphorus (SRP), $\mathbf{g}$ dissolved organic $\mathrm{P}$ (DOP), and $\mathbf{h}$ percent SRP in TDP (SRP:TDP). Dashed vertical lines separate the hydrologic phases, which are labeled with capital letters in the upper panels ( $\mathrm{C}$ contraction, $\mathrm{F}$ fragmentation, $\mathrm{E}$ expansion). Breaks in the $x$-axis indicate the dry (no surface water) period. Data are from samples taken at several locations along the study reach two times per week. Values are the medians \pm quartiles for each sampling date. Notice break in the $y$-axis of $\mathbf{b}$ for clarity of patterns

\section{Stoichiometric ratios}

Differences in $\mathrm{N}$ and $\mathrm{P}$ concentrations in response to ecosystem contraction, fragmentation and expansion affected N:P molar ratios. During the contraction and fragmentation phases, the TDN:TDP (Fig. 4a) and DIN:SRP (Fig. 4b) ratios remained relatively low and constant $(p>0.139, n=15)$, while the DON:DOP ratio tended to decrease $\left(r_{\mathrm{s}}=0.47, \quad p=0.074, \quad n=15\right.$; Fig. 4c). At the beginning of the expansion phase, the TDN:TDP and DIN:SRP ratios were high (up to median values of 36 and 43, respectively), but rapidly decreased to previous values afterwards $\left(r_{\mathrm{s}}=0.70, p=0.036\right.$, $n=9$ and $r_{\mathrm{s}}=0.65, p=0.058, n=9$, respectively; Fig. 4a, b). Conversely, the DON:DOP ratio increased gradually until the end of the study $\left(r_{\mathrm{s}}=-0.73\right.$, $p=0.025, n=9$; Fig. 4c).

\section{Spatial heterogeneity}

Ecosystem contraction, fragmentation and expansion affected the spatial heterogeneity of nutrient concentrations (Fig. 5). The wetted area was negatively related to the $\mathrm{CV}$ of $\mathrm{NH}_{4}\left(r_{\mathrm{s}}=-0.74, p<0.001, n=24\right), \mathrm{NO}_{3}$ $\left(r_{\mathrm{s}}=-0.51, \quad p=0.011, \quad n=24\right), \quad \mathrm{DON} \quad\left(r_{\mathrm{s}}=-0.37\right.$, $p=0.073, \quad n=24), \quad \operatorname{SRP} \quad\left(r_{\mathrm{s}}=-0.61, \quad p=0.001\right.$, $n=24)$ and DOP $\left(r_{\mathrm{s}}=-0.36, p=0.082, n=24\right)$, indicating that the spatial heterogeneity of all $\mathrm{N}$ and $\mathrm{P}$ forms was highest during stream fragmentation. Nevertheless, spatial heterogeneity differed among nutrients, with $\mathrm{NH}_{4}$ showing the highest and DON the lowest spatial heterogeneity (Fig. 5). Conversely, the $\mathrm{CV}$ of chloride was not related to wetted area $\left(r_{\mathrm{s}}=-0.12\right.$, $p=0.563, n=24)$ and remained low during the entire study (Fig. 5). The CV of DIN:TDN $\left(r_{\mathrm{s}}=-0.66\right.$, $p<0.001, \quad n=24) \quad$ and SRP:TDP $\quad\left(r_{\mathrm{s}}=-0.47\right.$, $p=0.021, n=24)$ increased with the reduction of wetted area. Also the CV of DIN:SRP increased with the reduction of wetted area $\left(r_{\mathrm{s}}=-0.78, \quad p<0.001\right.$, $n=24)$, whereas no relationship was found for the rest of N:P molar ratios $(p>0.126, n=24)$.

\section{Discussion}

Temporal variation in nutrient concentrations

Ecosystem contraction and fragmentation during surface drying disconnected the stream from its catchment as well as from upstream and downstream reaches, causing characteristic low oxygen and acidic conditions in the remaining water (Stanley et al. 1997; Acuña et al. 2005; Lillebo et al. 2007). The concentration and relative dominance of different dissolved $\mathrm{N}$ forms responded to these changes. Oxidized dissolved inorganic $\mathrm{N}\left(\mathrm{NO}_{3}\right)$ decreased close to the detection limit, likely reflecting its strong use as an electron acceptor in the denitrification process under low oxygen conditions (Seitzinger 1988). Conversely, the concentration of reduced dissolved inorganic $\mathrm{N}\left(\mathrm{NH}_{4}\right)$ increased during the fragmentation phase, probably due to leaching and rapid mineralization of detritus accumulated in isolated pools (Acuña et al. 2005), as well as to desorption from sediments and inhibition of nitrification (Baldwin and Mitchel 2000; Baldwin and Williams 2007). High evaporation rates (Gasith and Resh 1999), low ammonia diffusion rates at low pH (Sigman et al. 1997), and photodegradation of dissolved organic matter (Larson et al. 2007), although probably not important in this stream due to riparian shading, may also have contributed to the observed increases in $\mathrm{NH}_{4}$, the dominant DIN pool during the fragmentation phase. Alternatively, relatively high and stable DON concentrations during this phase suggest that a fraction of this $\mathrm{N}$ form could have been mineralized concomitantly to being produced, thus contributing to an additional source of $\mathrm{NH}_{4}$ (Berman and Bronk 2003).

Despite marked changes in the dissolved inorganic $\mathrm{N}$ pool, about $82 \%$ of available dissolved $\mathrm{N}$ remained in organic form (as DON) during stream contraction and fragmentation. Overall, the loss of $\mathrm{NO}_{3}$ was compensated by the increase in $\mathrm{NH}_{4}$, and in-stream processing did not alter the relative availability of dissolved organic and inorganic $\mathrm{N}$ forms. Previous studies in this stream showed that during baseflow or fragmented flow conditions, a high proportion of TDN is available as DON (Bernal et al. 2005; Vazquez et al. 2011). Interestingly, this balance was interrupted by a sharp increase in DON concentration at the end of the fragmentation phase, probably due to an abrupt microbial biofilm cell lysis or DON exudation under stress conditions (e.g. high temperature, low DO, low pH), which was not further mineralized (Humphries and Baldwin 2003; Schimel et al. 2007). Alternatively, the low DO and $\mathrm{pH}$ conditions may have caused high release of dissolved organic matter adsorbed to sediments (Kalbitz et al. 2000).

The concentration of dissolved $\mathrm{P}$ slightly increased during stream contraction and fragmentation, due to concomitant increases in the dissolved inorganic and organic $\mathrm{P}$ 

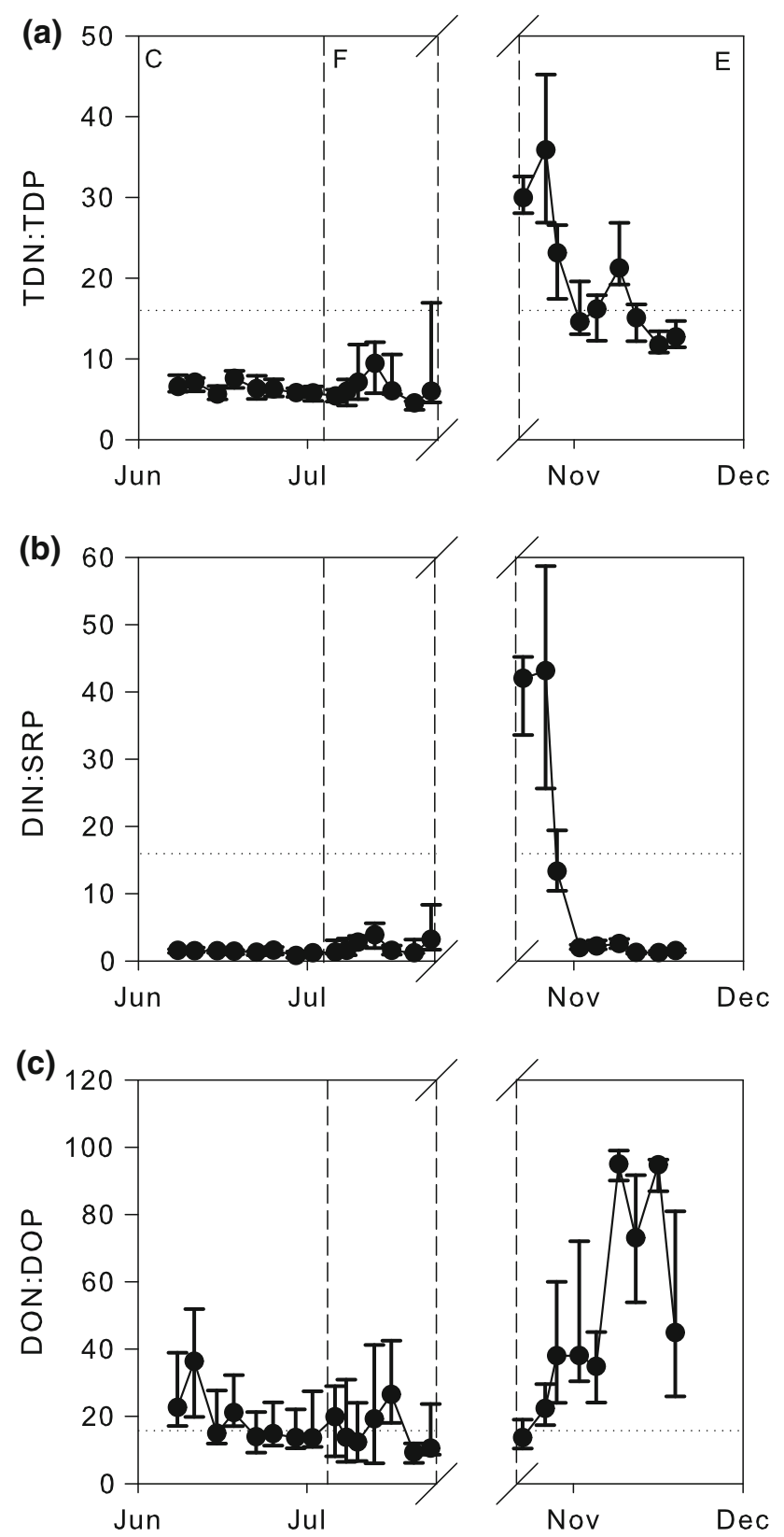

Fig. 4 Temporal variation of nitrogen $(\mathrm{N})$ to phosphorus $(\mathrm{P})$ molar ratios. Represented are the ratios of: a total dissolved forms (TDN:TDP), b inorganic forms (DIN:SRP), and c) organic forms (DON:DOP). Dashed vertical lines separate the hydrologic phases, which are labeled with capital letters in the upper panel $(\mathrm{C}$ contraction, F fragmentation, E expansion). Dotted horizontal lines represent the Redfield N:P ratio of 16:1. Breaks in the $x$-axis indicate the dry (no surface water) period. Data are from samples taken at several locations along the study reach two times per week. Values are the medians \pm quartiles for each sampling date

forms. These increases were probably explained by similar mechanisms as for $\mathrm{N}$, such as mineralization of accumulated detritus (Acuña et al. 2005), desorption (Baldwin and Mitchel 2000), concentration through water evaporation (Gasith and Resh 1999), and photodegradation (Larson

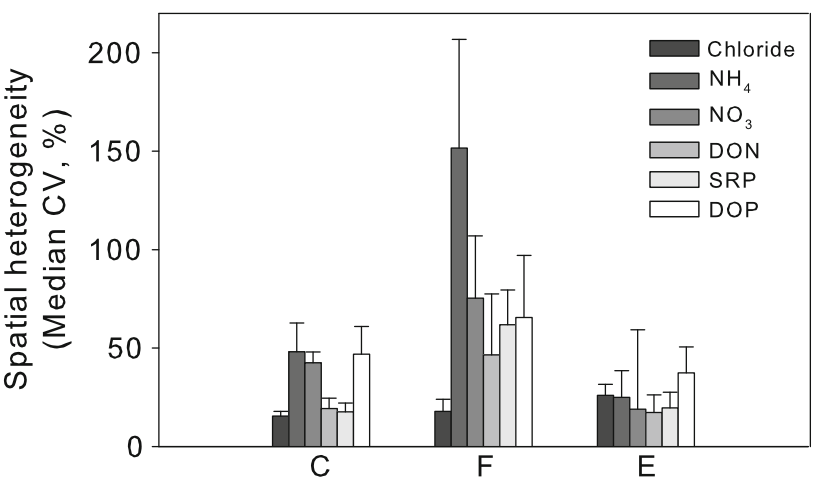

Fig. 5 Spatial heterogeneity represented as the median coefficient of variation $(\mathrm{CV}) \pm$ quartiles for all nutrients and the conservative tracer during the different hydrologic phases (C contraction, $\mathrm{F}$ fragmentation, E expansion). Represented are: chloride, ammonium $\left(\mathrm{NH}_{4}\right)$, nitrate $\left(\mathrm{NO}_{3}\right)$, dissolved organic $\mathrm{N}(\mathrm{DON})$, soluble reactive $\mathrm{P}$ (SRP), and dissolved organic $\mathrm{P}$ (DOP). Data from the small rewetting event during the fragmented phase were not included

et al. 2007). However, in contrast to $\mathrm{N}$, release of $\mathrm{P}$ was not compensated by uptake or transformation, and thus the concentration of dissolved $\mathrm{P}$ forms tended to increase. In addition, only about $34 \%$ of available dissolved $\mathrm{P}$ was in organic form (as DOP), and this proportion did not change substantially during stream contraction and fragmentation. Although this type of data is rarely reported in the literature, forest streams tend to show a higher proportion of DOP relative to SRP than that found in this study (Turner et al. 2003; Stutter et al. 2008; Skoulikidis and Amaxidis 2009). The relatively low proportion of DOP found in Fuirosos may be due to the fact that the stream is highly heterotrophic during this period (Acuña et al. 2004), so that microbial and primary producers may be obtaining an important part of $\mathrm{P}$ from dissolved organic matter. Unfortunately, there is no DOP data available for this stream during other periods of the year for comparison. As for DON, microbial biofilm cell lysis, DOP exudation, and desorption processes probably contributed to the sharp increase in DOP concentration at the end of the fragmentation phase (Humphries and Baldwin 2003; Schimel et al. 2007; Kalbitz et al. 2000). Overall, our results for N and P contradict the hypothesis by Dahm et al. (2003) who suggested that under drought conditions, the ratio of organic to inorganic nutrients would decrease, thus favoring autotrophic over heterotrophic growth. This hypothesis may be valid for open canopy streams such as desert streams, but cannot be applied to streams with a well developed riparian canopy cover such as Fuirosos.

Upon rewetting, the lateral, vertical and longitudinal hydrologic connections along the stream channel were reestablished. This stream ecosystem expansion favored the release of high amounts of dissolved $\mathrm{N}$ and $\mathrm{P}$ from the riparian zone through the elevation of the groundwater table (Butturini et al. 2003; Vazquez et al. 2007) and from 
upstream reaches through the leaching of accumulated detritus (Ylla et al. 2010) and microbial cell lysis (Schimel et al. 2007). It also favored desorption and re-dissolution of salts from sediments (Baldwin and Mitchel 2000). The increase in $\mathrm{N}$ and $\mathrm{P}$ concentrations through these processes was possibly enhanced by stream sediment desiccation during the dry phase. As in upland soils, desiccation likely caused physical disruption as well as changes in redox conditions and hydrophobicity of stream and riparian sediments (Borken and Matzer 2009). In addition, fresh leaves and other organic material such as microbial and algal detritus accumulated on the streambed due to early leaf fall and lack of transport (Acuña et al. 2007). These materials decomposed slowly under drying conditions, but were likely subject to chemical preconditioning (Boulton 1991).

The concentration of dissolved $\mathrm{N}$ increased considerably immediately after rewetting, basically due to a dramatic increase in $\mathrm{NO}_{3}$ concentration in response to release from riparian groundwater and fast nitrification of the leaching from accumulated detritus (Butturini et al. 2003; Bernal et al. 2005). The concentration of DON also increased but to a lower proportion than that of $\mathrm{NO}_{3}$. As a result, about $81 \%$ of available dissolved $\mathrm{N}$ was in inorganic form (primarily as $\mathrm{NO}_{3}$ ) at the beginning of the expansion phase. This contrasts with other streams where $\mathrm{NH}_{4}$ is the most abundant $\mathrm{N}$ form after initial rewetting (Skoulikidis and Amaxidis 2009; Obermann et al. 2009). Probably the high nitrification rates in soils during the precedent dry period caused the low proportion of $\mathrm{NH}_{4}$ at rewetting in our stream (Bernal et al. 2005). In contrast to N, both SRP and DOP increased after rewetting, and the proportion of organic and inorganic forms of $\mathrm{P}$ remained relatively stable and at similar values as in the previous hydrologic phases, indicating that dissolved inorganic and organic forms of $\mathrm{P}$ were originated from similar sources at the different hydrologic phases.

After the initial increase at the beginning of the expansion phase, the concentrations of the different $\mathrm{N}$ and $\mathrm{P}$ forms rapidly decreased. This decline may be at least partially explained by reduced nutrient leaching and lateral groundwater inputs, but also by higher microbial processing of $\mathrm{N}$ and $\mathrm{P}$ due to the high availability of labile organic matter and stable flow conditions (Romaní et al. 2006; Vazquez et al. 2007; Ylla et al. 2010). It is worth noting that these changes were different for $\mathrm{N}$ and $\mathrm{P}$ forms. The proportion of dissolved organic and inorganic forms of $\mathrm{N}$ (i.e. the DIN:TDN proportion) decreased to $8 \%$ by the end of the study period, a value lower than that found during the contraction and fragmentation phases. Conversely, the SRP:TDP proportion did not vary substantially and remained at similar values as in the previous hydrologic phases. These differences suggest higher microbial processing rates of organic $\mathrm{N}$ over $\mathrm{P}$ compounds, as indicated in previous studies (Fazi et al. 2008).

Temporal variation in nutrient stoichiometry

Overall, temporal changes in concentration were more pronounced for $\mathrm{N}$ than for $\mathrm{P}$, resulting in the observed stoichiometric shifts among hydrologic phases. During ecosystem contraction and fragmentation, the N:P molar ratios of total dissolved forms (TDN:TDP) and inorganic forms (DIN:SRP) were well below the Redfield ratio (16:1), indicating potential N limitation (Sterner and Elser 2002). These ratios were lower than those previously reported for this stream, which is considered potentially P-limited for most of the hydrologic period (Sabater et al. 2005; von Schiller et al. 2008). Present results indicate that the stream may become N-limited under ecosystem contraction and fragmentation conditions. In addition, the gradual decrease in the molar ratio of organic forms (DON:DOP) to below the Redfield ratio during this period indicates an enhanced microbial use of DON over DOP under N limitation (Tuchman 1996).

The stoichiometric ratios were also markedly altered as the ecosystem expanded upon rewetting, when ratios of total dissolved forms (TDN:TDP) and inorganic forms (DIN:SRP) increased above the Redfield ratio, indicating a clear shift to potential P limitation (Sterner and Elser 2002). This change was primarily driven by the abrupt increase in $\mathrm{NO}_{3}$. High $\mathrm{N}: \mathrm{P}$ ratios at rewetting have been reported from previous studies, and are probably a result of higher relative release of $\mathrm{N}$ over $\mathrm{P}$ from soils (Tzoraki et al. 2007; Obermann et al. 2009; Skoulikidis and Amaxidis 2009). During the expansion phase, the TDN:TDP ratio gradually decreased and stabilized around the Redfield ratio, while the DIN:SRP ratio decreased to values similar to the contraction and fragmentation phases, indicating no nutrient limitation or a slight potential $\mathrm{N}$ limitation (Sterner and Elser 2002). The increase in the DON:DOP ratio at the end of the study period was likely due to the microbial use of DOP as a $\mathrm{P}$ source during a period of relatively high $\mathrm{N}$ and organic carbon availability and limitation of inorganic forms as a P source (Tuchman 1996).

\section{Spatial heterogeneity in $\mathrm{N}$ and $\mathrm{P}$ concentrations}

In addition to enhancing the influence of local in-stream processes on nutrient concentrations, ecosystem fragmentation caused an increase in the spatial heterogeneity of dissolved $\mathrm{N}$ and $\mathrm{P}$ concentrations compared to that of the conservative tracer (chloride), probably driven by a high divergence in abiotic and biotic nutrient cycling processes among isolated pools. Previous studies have demonstrated large spatial heterogeneity along stretches of several 


\section{Ecosystem contraction and fragmentation (drying)}

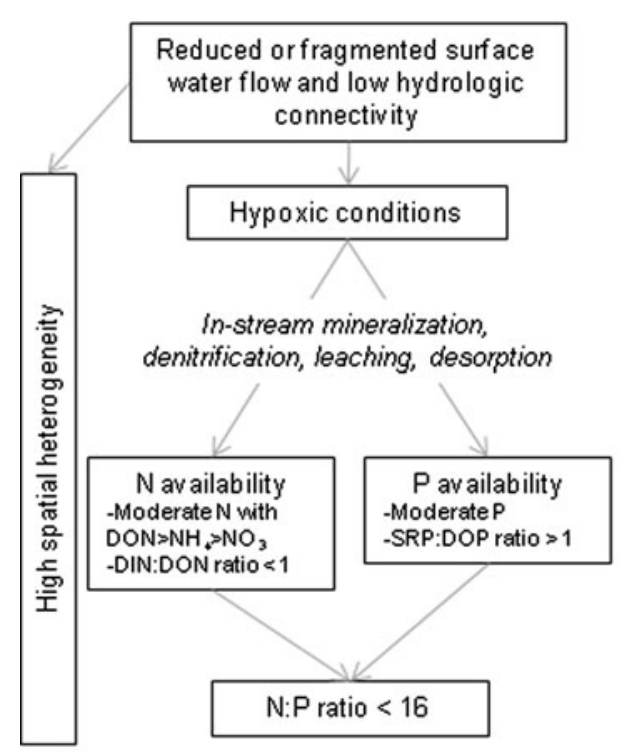

Fig. 6 Conceptual summary of major changes in dissolved nitrogen $(\mathrm{N})$ and phosphorus $(\mathrm{P})$ availability in Fuirosos stream surface water as the ecosystem contracts and fragments during drying, and expands during rewetting. Proposed dominant processes leading to changes in nutrient availability are shown in italics. Overall, in-stream processes drive nutrient availability during ecosystem contraction and

kilometers, which can be more pronounced under fragmented flow conditions (Dent and Grimm 1999; Likens and Buso 2006). This study clearly demonstrates that stream fragmentation may cause high spatial heterogeneity in $\mathrm{N}$ and $\mathrm{P}$ concentrations even at smaller spatial scales. For instance, the range in the concentration of $\mathrm{NH}_{4}$ on 16 July (0.016-1.096 $\left.\mathrm{m} \mathrm{N} \mathrm{L}^{-1}\right)$, when the stream was fragmented, was similar to that found over the whole period covered by this study $\left(0.002-1.096 \mathrm{mg} \mathrm{N} \mathrm{L}^{-1}\right)$ and even greater than the range found in a previous study in the same stream covering two hydrologic years $(0.005-0.201$ mg N L ${ }^{-1}$; von Schiller et al. 2008). Although $\mathrm{NH}_{4}$ was the nutrient showing the highest spatial heterogeneity, the spatial heterogeneity of all dissolved organic and inorganic forms of $\mathrm{N}$ and $\mathrm{P}$ increased with stream fragmentation. Our results support findings from previous studies showing increased spatial heterogeneity of $\mathrm{N}$ availability during stream fragmentation in arid streams in Arizona (Dent and Grimm 1999) and SE Spain (Gómez et al. 2009), but contradict findings by Baldwin et al. (2005) who showed low spatial heterogeneity of $\mathrm{N}$ concentrations in isolated pools from an Australian stream. Results from the present study expand these observations

\section{Ecosystem expansion (rewetting)}

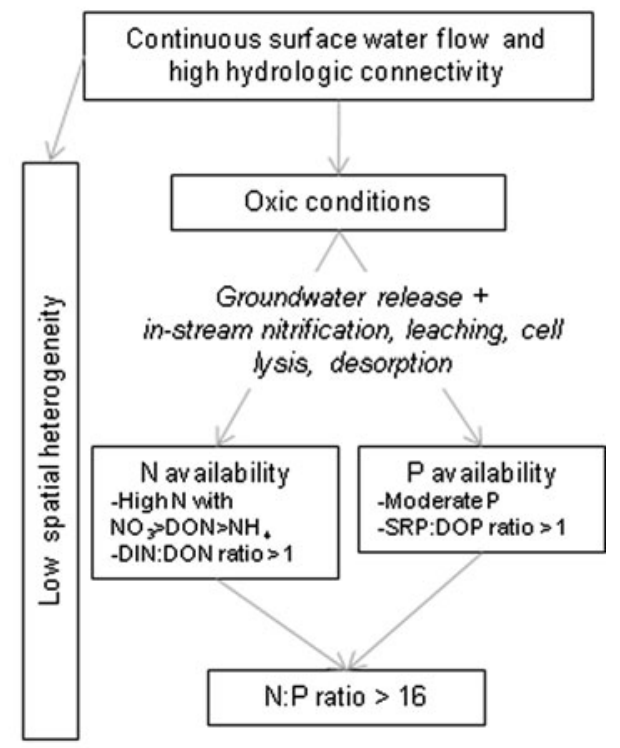

fragmentation. Groundwater inputs of riparian and catchment origin drive nutrient availability during ecosystem expansion. Spatial heterogeneity increases with stream fragmentation due to the reduction of hydrologic connectivity and the higher relevance of instream processes. Changes are more pronounced overall for $\mathrm{N}$ than for $\mathrm{P}$, resulting in shifts in $\mathrm{N}: \mathrm{P}$ ratios

to the availability of dissolved inorganic and organic forms of $\mathrm{N}$ and $\mathrm{P}$.

\section{Conclusions}

Flow intermittency strongly influenced nutrient availability in the study stream at a small small spatial scale and over a relatively short period (summarized in Fig. 6). According to our hypotheses, we observed clear temporal changes in dissolved $\mathrm{N}$ and $\mathrm{P}$ concentrations as well as in the proportion of organic and inorganic forms, indicating shifts in the relative importance of in-stream nutrient processing and external nutrient sources as the stream ecosystem contracted, fragmented and expanded. Temporal variation was generally more pronounced for $\mathrm{N}$ than for $\mathrm{P}$, causing important changes in stoichiometric ratios during this hydrologic period. In addition, we found a marked increase in the spatial heterogeneity of nutrient concentrations and ratios during stream fragmentation, indicating the high relevance of in-stream processes when advective transport was lost.

Although spatially restricted to a Mediterranean forest stream, our results suggest that flow intermittency may 
be a key determinant of nutrient availability and subsequent downstream export in streams. This is relevant within the context of water legislation, such as the EU WFD (2000), in which nutrient conditions are used for the assessment of the ecological and chemical status of running waters. Our results show that temporary streams, which are the dominant surface water type in arid and semiarid regions such as the Mediterranean basin, may show an intrinsic high temporal and spatial variability in nutrient concentrations. Consequently, reference conditions used to evaluate the ecological and chemical status of permanent streams may not be appropriate for temporary streams.

Moreover, because permanent streams in the temperate zone are increasingly becoming temporary, results from this and similar studies may serve as a template for understanding the potential biogeochemical consequences of stream drying in the temperate zone. Our results suggest that under future water scarcity scenarios, streams from more temperate regions may be subject to higher chemical variability and stoichiometric shifts with critical extremes both in time and space. This will most likely affect stream ecosystem structure and function, by altering microbial activity and primary production as well as the local abundance and distribution of organisms, and may further have consequences for nutrient balances in downstream freshwater and coastal ecosystems.

Future research should focus on the effect of drying and rewetting on the underlying physical and microbial mechanisms driving the observed changes in nutrient availability (Fazi et al. 2008; Amalfitano et al. 2008; Marxsen et al. 2010) as well as on the biogeochemical processes occurring during the dry phase, when no surface water is present (Borken and Matzer 2009). At the catchment scale, a more thorough assessment of the temporal and spatial extent as well as of the physicochemical characteristics of temporary streams is needed (Larned et al. 2010). A special effort should be made in developing models to simulate nutrient and organic carbon processes and balances under the effects of flow intermittency (Tzoraki et al. 2009; Acuña and Tockner 2010), which may ultimately help to assess and manage these abundant but mostly neglected stream ecosystem types.

Acknowledgments We thank J. Rodríguez, L. Proia, M. Peipoch and A. Blesa for field assistance, E. Zwirnmann, H.-J. Exner, A. Lüder, S. Schell and H. Magnussen for laboratory analyses, and L. Perkin for English editing. We are also grateful to the direction of the Montnegre-Corredor Natural Park (Diputació de Barcelona) for allowing access to the sampling site and for providing meteorological data. This study was funded by the European Union through the Mediterranean Intermittent River ManAGEment (MIRAGE) project (ref: FP7 ENV 2007 1, http://www.mirage-project.eu). Additional funds were provided by the project CGL2007-65549/BOS and the Consolider-Ingenio projects CSD2009-00065 (SCARCE) and
CSD2007-00067 (GRACCIE) of the Spanish Ministry of Science and Innovation. D. von Schiller was supported by a fellowship of the German Academic Exchange Service and "laCaixa" Foundation.

Conflict of interest None.

\section{References}

Acuña V, Tockner K (2010) The effects of alterations in temperature and flow regime on organic carbon dynamics in Mediterranean river networks. Glob Change Biol 16:2638-2650

Acuña V, Giorgi A, Muñoz I, Uehlinger U, Sabater S (2004) Flow extremes and benthic organic matter shape the metabolism of a headwater Mediterranean stream. Freshw Biol 49:960-971

Acuña V, Muñoz I, Giorgi A, Omella M, Sabater F, Sabater S (2005) Drought and postdrought recovery cycles in an intermittent Mediterranean stream: structural and functional aspects. J N Am Benthol Soc 24:919-933

Acuña V, Giorgi A, Muñoz I, Sabater F, Sabater S (2007) Meteorological and riparian influences on organic matter dynamics in a forested Mediterranean stream. J N Am Benthol Soc 26:54-69

Amalfitano S, Fazi S, Zoppini A, Caracciolo AB, Grenni P, Puddu A (2008) Responses of benthic bacteria to experimental drying in sediments from Mediterranean temporary rivers. Microb Ecol 55:270-279

Arnell NW (1999) The effect of climate change on hydrological regimes in Europe: a continental perspective. Glob Environ Change 9:5-23

Baldwin DS, Mitchel AM (2000) The effects of drying and reflooding on the sediment and soil nutrient dynamics of lowland river-floodplain systems: a synthesis. Regul River 16:457-467

Baldwin DS, Williams J (2007) Differential release of nitrogen and phosphorus from anoxic sediments. Chem Ecol 3:243-249

Baldwin DS, Rees GN, Mitchell AM, Watson G (2005) Spatial and temporal variability of nitrogen dynamics in an upland stream before and after a drought. Mar Freshw Res 56:457-464

Berman T, Bronk DA (2003) Dissolved organic nitrogen: a dynamic participant in aquatic ecosystems. Aquat Microb Ecol 31:279-305

Bernal S, Butturini A, Sabater F (2005) Seasonal variations of dissolved nitrogen and DOC:DON ratios in an intermittent Mediterranean stream. Biogeochemistry 75:351-372

Borken W, Matzer E (2009) Reappraisal of drying and wetting effects on $\mathrm{C}$ and $\mathrm{N}$ mineralization and fluxes in soils. Glob Change Biol $15: 808-824$

Boulton AJ (1991) Eucalypt leaf decomposition in an intermittent stream in South-Eastern Australia. Hydrobiologia 211:123-136

Boulton AJ, Lake PS (1990) The ecology of two intermittent streams in Victoria, Australia. I. Multivariate analyses of physicochemical features. Freshw Biol 24:123-141

Butturini A, Bernal S, Nin E, Hellin C, Rivero L, Sabater S, Sabater F (2003) Influences of the stream groundwater hydrology on nitrate concentration in unsaturated riparian area bounded by an intermittent Mediterranean stream. Water Resour Res. doi: 10.1029/2001WR001260

Dahm CN, Baker MA, Moore DI, Thibault JR (2003) Coupled biogeochemical and hydrological responses of streams and rivers to drought. Freshw Biol 48:1219-1231

Dent CL, Grimm NB (1999) Spatial heterogeneity of stream water nutrient concentrations over successional time. Ecology 80:2283-2298

Fazi S, Amalfitano S, Piccini C, Zoppini A, Puddu A, Pernthaler J (2008) Colonization of overlaying water by bacteria from dry river sediments. Environ Microbiol 10:2760-2772 
Fisher SG, Sponseller RA, Heffernan JB (2004) Horizons in stream biogeochemistry: flowpaths to progress. Ecology 85:2369-2379

Gasith A, Resh VH (1999) Streams in Mediterranean climate regions: abiotic influences and biotic responses to predictable seasonal events. Annu Rev Ecol Syst 30:51-81

Gómez R, García V, Vidal-Abarca R, Suárez L (2009) Effect of intermittency on $\mathrm{N}$ spatial variability in an arid Mediterranean stream. J N Am Benthol Soc 28:572-583

Howard-Williams C, Vincent CL, Broady PA, Vincent WF (1986) Antarctic stream ecosystems: variability in environmental properties and algal community structure. Int Rev Hydrobiol 71:511-544

Humphries P, Baldwin DS (2003) Drought and aquatic ecosystems: an introduction. Freshw Biol 48:1141-1146

Huntington TG (2006) Evidence for intensification of the global water cycle: review and synthesis. J Hydrol 319:83-95

IPCC (Intergovernmental Panel on Climate Change) (2007) Fourth assessment report. Climate change 2007: climate change impacts, adaptation and vulnerability. http://www.ipcc.ch/

Kalbitz K, Solinger S, Park JH, Michalzik B, Matzner E (2000) Controls on the dynamics of dissolved organic matter in soils: a review. Soil Sci 165:277-304

Larned ST, Datry T, Arscott DB, Tockner K (2010) Emerging concepts in temporary-river ecology. Freshw Biol 55:717-738

Larson JH, Frost PC, Lodge DM, Lamberti GA (2007) Photodegradation of dissolved organic matter in forested streams of the northern Great Lakes region. J N Am Benthol Soc 26:416-425

Likens GE, Buso DC (2006) Variation in streamwater chemistry throughout the Hubbard Brook valley. Biogeochemistry 78:1-30

Lillebo AI, Morais M, Guilherme P, Fonseca R, Serafim A, Neves R (2007) Nutrient dynamics in Mediterranean temporary streams: a case study in Pardiela catchment (Degebe River, Portugal). Limnologica 37:337-348

Marxsen J, Zoppini A, Wilczek S (2010) Microbial communities in streambed sediments recovering from desiccation. FEMS Microbiol Ecol 71:374-386

Merriam J, McDowell WH, Currie WS (1996) A high-temperature catalytic oxidation technique for determining total dissolved nitrogen. Soil Sci Soc Am J 60:1050-1055

Milliman JD, Farnsworth KL, Jones PD, Xu KH, Smith LC (2008) Climatic and anthropogenic factors affecting river discharge to the global ocean, 1951-2000. Glob Planet Change 62:187-194

Murphy J, Riley JP (1962) A modified single solution method for the determination of phosphate in natural waters. Anal Chim Acta $27: 31-36$

Nadeau TL, Rains MC (2007) Hydrological connectivity between headwater streams and downstream waters: how science can inform policy. J Am Water Resour Assoc 43:118-133

Obermann M, Rosenwinkel KH, Tournoud MG (2009) Investigation of first flushes in a medium-sized Mediterranean catchment. J Hydrol 373:405-415

Pasquini AI, Depetris PJ (2007) Discharge trends and flow dynamics of South American rivers draining the southern Atlantic seaboard: an overview. J Hydrol 333:385-399

Pringle CM (1990) Nutrient spatial heterogeneity: effects on community structure, physiognomy, and diversity of stream algae. Ecology 71:905-920

Reardon J, Foreman JA, Searcy RL (1966) New reactants for the colorimetric determination of ammonia. Clin Chim Acta 14:203-205

Romaní AM, Vazquez E, Butturini A (2006) Microbial availability and size fractionation of dissolved organic carbon after drought in an intermittent stream: biogeochemical link across the streamriparian interface. Microb Ecol 52:501-512
Sabater S, Bernal S, Butturini A, Nin E, Sabater F (2001) Wood and leaf debris input in a Mediterranean stream: the influence of riparian vegetation. Arch Hydrobiol 153:91-102

Sabater S, Acuña V, Giorgi A, Guerra E, Muñoz I, Romaní AM (2005) Effects of nutrient inputs in a forested Mediterranean stream under moderate light availability. Arch Hydrobiol 163:479-496

Schimel JP, Balser TC, Wallenstein M (2007) Microbial stressresponse physiology and its implications for ecosystem function. Ecology 88:1386-1394

Seitzinger SP (1988) Denitrification in freshwater and coastal marine ecosystems: ecological and geochemical significance. Limnol Oceanogr 33:702-724

Sigman DM, Altabet MA, Michener R, McCorkle DC, Fryd B, Holmes RM (1997) Natural abundance-level measurement of the nitrogen isotopic composition of oceanic nitrate: an adaptation of the ammonia diffusion method. Mar Chem 57:227-242

Skoulikidis N, Amaxidis Y (2009) Origin and dynamics of dissolved and particulate nutrients in a minimally disturbed Mediterranean river with intermittent flow. J Hydrol 373:218-229

Stahl K, Hisdal H, Hannaford J, Tallaksen LM, van Lanen HAJ, Sauquet E, Demuth S, Fendekova M, Jódar J (2010) Streamflow trends in Europe: evidence from a dataset of near-natural catchments. Hydrol Earth Syst Sci 14:2367-2382

Stanley EH, Fisher SG, Grimm NB (1997) Ecosystem expansion and contraction in streams. Bioscience 47:427-435

Sterner RW, Elser JJ (2002) Ecological stoichiometry: the biology of elements from molecules to the biosphere. Princeton University Press, Princeton

Stutter MI, Langan SJ, Cooper RJ (2008) Spatial and temporal dynamics of stream water particulate and dissolved N, P and $\mathrm{C}$ forms along a catchment transect, NE Scotland. J Hydrol 350:187-202

Tornés E, Sabater S (2010) Variable discharge alters habitat suitability for benthic algae and cyanobacteria in a forested Mediterranean stream. Mar Freshw Res 61:441-450

Tuchman NC (1996) The role of heterotrophy in algae. In: Stevenson RJ, Bothwell ML, Lowe RL (eds) Algal ecology: freshwater benthic ecosystems, 1st edn. Academic Press, San Diego

Turner BL, Baxter R, Whitton BA (2003) Nitrogen and phosphorus in soil solutions and drainage streams in Upper Teesdale northern England: implications of organic compounds for biological nutrient limitation. Sci Total Environ 314-316:153-170

Tzoraki O, Nikolaidis NP, Amaxidis Y, Skoulikidis NT (2007) Instream biogeochemical processes of a temporary river. Environ Sci Technol 41:1225-1231

Tzoraki O, Nikolaidis NP, Trancoso AR, Braunschweig F, Neves R (2009) A reach-scale biogeochemical model for temporary rivers. Hydrol Process 23:272-283

Uys MC, O'Keefe JH (1997) Simple words and fuzzy zones: early directions for temporary river research in South Africa. Environ Manag 21:517-531

Vazquez E, Romaní AM, Sabater F, Butturini A (2007) Effects of the dry-wet hydrological shift on dissolved organic carbon dynamics and fate across stream-riparian interface in a Mediterranean catchment. Ecosystems 10:239-251

Vazquez E, Amalfitano S, Fazi A, Butturini A (2011) Dissolved organic matter composition in a fragmented Mediterranean fluvial system under severe drought conditions. Biogeochemistry 102:59-72

Vidal-Abarca MR, Suarez ML, Moreno JL, Gomez R, Sanchez I (2000) Hidroquímica de un río de características semiáridas. Limnetica 18:57-73

von Schiller D, Martí E, Riera JL, Ribot M, Argerich A, Fonollà P, Sabater F (2008) Inter-annual, annual, and seasonal variation of $\mathrm{P}$ and $\mathrm{N}$ retention in a perennial and an intermittent stream. Ecosystems 11:670-687

WFD (Water Framework Directive) (2000) Directive 2000/60/EC of the European Parliament and of the Council of 23 October 
2000 establishing a framework for Community action in the field of water policy. http://eur-lex.europa.eu/LexUriServ/LexUriServ. do?uri=CELEX:32000L0060:EN:NOT

Williams DD (2006) The biology of temporary waters. Oxford University Press, Oxford

Yang SL, Zhao QY, Belkin IM (2002) Temporal variation in the sediment load of the Yangtze river and the influences of human activities. J Hydrol 263:56-71
Ylla I, Sanpera-Calbet I, Vazquez E, Romaní AM, Muñoz I, Butturini A, Sabater S (2010) Organic matter availability during pre- and post-drought periods in a Mediterranean stream. Hydrobiologia 657:217-232

Zwirnmann E, Krüger A, Gelbrecht J (1999) Analytik im zentralen Chemielabor des IGB. Berichte des IGB 9:3-24 